\title{
Evaporação da água na superfície do solo em sistemas de plantio direto e preparo convencional
}

\author{
Genei Antonio Dalmago(1), Homero Bergamaschi(2), Cleusa Adriane Menegassi Bianchi Krüger ${ }^{(3)}$, \\ João Ito Bergonci( ${ }^{(4)}$, Flávia Comiran ${ }^{(5)}$ e Bruna Maria Machado Heckler ${ }^{(6)}$
}

\begin{abstract}
(1)Embrapa Trigo, Caixa Postal 451, CEP 99001-970 Passo Fundo, RS. E-mail: dalmago@cnpt.embrapa.br (2)Universidade Federal do Rio Grande do Sul (UFRGS), Faculdade de Agronomia, Avenida Bento Gonçalves, no 7712, Caixa Postal 15.100, CEP 91501-970 Porto Alegre, RS. E-mail: homerobe@ufrgs.br (3)Universidade Regional de ljuí, Departamento de Estudos Agrários, Rua do Comércio, no 3.000, CEP 98700-000 ljuí, RS. E-mail: cleusa.bianchi@unijui.edu.br (4)UFRGS, Departamento de Botânica, Avenida Paulo Gama, s/no, CEP $90046-900$ Porto Alegre, RS. E-mail: joao.bergonci@ufrgs.br ${ }^{(5)}$ Instituto Agronômico do Paraná, BR 376, Km 496, Caixa Postal 129, CEP $84001-970$ Ponta Grossa, PR. E-mail: fcomiran@iapar.br ${ }^{\left({ }^{6}\right)}$ Empresa de Assistência Técnica e Extensão Rural, Alameda Veredinha, s/noo, Área Especial, Setor Tradicional, CEP 72720-660 Brazlândia, DF. E-mail: bruheckler@hotmail.com
\end{abstract}

Resumo - Este trabalho teve por objetivos quantificar a evaporação da água na superfície do solo, em plantio direto e em preparo convencional, e avaliar o uso de microlisímetros de pesagem para medir esse processo. As medições foram feitas em campo, nos verões de 2001/2002, 2002/2003 e 2004/2005, em experimentos irrigados e não irrigados. Utilizaram-se delineamentos inteiramente casualizados, com quatro repetições, cujos tratamentos consistiram de sistemas de manejo do solo - plantio direto e preparo convencional -, e a presença ou ausência de cultivo de milho. Mediu-se a evaporação diária durante períodos de secagem do solo, entre precipitações ou irrigações consecutivas. Em experimentos sem irrigação, a evaporação acumulada foi maior sob plantio direto, na maioria dos períodos de medição, independentemente da presença da lavoura de milho. Nos experimentos com irrigação, a evaporação não apresentou diferenças regulares entre sistemas de manejo de solo. Normalmente, no início dos períodos de medição, com dois a cinco dias de secagem do solo, a evaporação foi maior em solo sob preparo convencional, tendo-se tornado maior em plantio direto, no restante do período de secagem. O emprego de microlisímetros de pesagem é eficiente para medir a evaporação na superfície do solo.

Termos para indexação: Zea mays, água no solo, balanço hídrico, microlisímetro, preparo do solo, semeadura direta.

\section{Soil surface water evaporation under no-tillage and conventional tillage systems}

\begin{abstract}
This work aimed to quantify the evaporation of water on the soil surface under no-tillage and conventional tillage systems, and to evaluate the microlysimeters use to measure this process. Measurements were performed in the field, during the summers of 2001/2002, 2002/2003 and 2004/2005, in experiments with and without irrigation. Completely randomized designs were used, with four repetitions. The treatments consisted of no-tillage and conventional soil tillage systems, in the presence or absence of corn cultivation. Evaporation was measured daily, during drying periods between precipitations and consecutive irrigations. Without irrigation, accumulated evaporation was greater under no tillage system, in most measuring periods, irrespective of the presence of corn cultivation. In experiments with irrigation, evaporation was similar in both types of soil management systems. Normally, at the beginning of the measurement periods, within two to five days of drying, evaporation was higher in soil under conventional tillage and, subsequently, it became greater in soils under no tillage system. The use of microlysimeters proved to be efficient to measure the evaporation at the soil surface.
\end{abstract}

Index terms: Zea mays, soil water, water budget, microlysimeter, soil tillage, direct seeding.

\section{Introdução}

O sistema de plantio direto altera as características físico-hídricas do solo, em relação ao sistema de preparo convencional. Diante dessas alterações, o padrão dos fluxos de água no espaço e no tempo, no sistema solo-planta-atmosfera, é alterado (Fabrizzi et al., 2005; Moret \& Arrúe, 2007). Entre as alterações

Pesq. agropec. bras., Brasília, v.45, n.8, p.780-790, ago. 2010 
esperadas, estão as relacionadas à perda de água por evaporação na superfície do solo. Esses processos têm sido pouco estudados em áreas de plantio direto no Brasil.

A variabilidade da evaporação entre sistemas de preparo do solo pode ser atribuída a dois fatores principais: o padrão de cobertura de palha na superfície e as alterações na estrutura porosa do solo (Hatfield et al., 2001; Yang \& Yanful, 2002; Aydin et al., 2005; Hubert et al., 2007). A palha modifica a perda de água na superfície do solo por alterar a ação dos elementos meteorológicos que compõem a demanda evaporativa da atmosfera (Aydin et al., 2005; Chen et al., 2007), e também por formar uma espécie de camada isolante ao fluxo hídrico, por causa do ar que permanece relativamente parado dentro da camada de palha (Lemon, 1956). No que se refere aos fatores de solo que interferem na evaporação, a estrutura, a densidade, a porosidade e a condutividade hidráulica não saturada são os mais importantes (Yang \& Yanful, 2002), e afetam o teor de umidade e o fluxo de água no perfil do solo (Lemon, 1956; Yang \& Yanful, 2002).

Embora o efeito do revolvimento ou não do solo e a presença de palha influenciem na perda de água por evaporação, a maioria dos trabalhos indica apenas a palha como fator redutor da evaporação e, por conseguinte, como condicionante do aumento da umidade no solo em plantio direto (Bragagnolo \& Mielniczuk, 1990; Fabrizzi et al., 2005; De Vita et al., 2007). Entretanto, a maior parte desses estudos não avaliou diretamente a evaporação da água do solo, tendo-se baseado em determinações indiretas, principalmente na variação da umidade do solo em momentos pontuais. Dessa forma, a dinâmica da água em plantio direto nem sempre tem sido avaliada de forma apropriada, uma vez que a evaporação da água do solo é um processo complexo, influenciado por diversos fatores (Yang \& Yanful, 2002).

Para avaliar a evaporação da água do solo no sistema plantio direto, poucos estudos foram baseados em medições diretas da perda de água por evaporação. Aase \& Tanaka (1987) mediram o processo em função da quantidade de resíduos na superfície do solo, com uso de lisímetros de pesagem, e não encontraram diferença significativa entre a evaporação em solo desnudo e com diferentes formas de manejo da palha. Segundo esses autores, após dez dias de secagem do solo, todos os tratamentos apresentaram perdas acumuladas muito próximas, o que sugere que o maior efeito da palha ocorra no início da secagem do solo. Por sua vez, em ambiente controlado, Sauer et al. (1996) observaram menor evaporação em colunas de solo coberto com palha, em comparação ao solo desnudo, e encontraram similaridade com estimativas feitas no campo. Esses autores observaram redução da evaporação com o aumento da quantidade de palha na superfície, o que também foi verificado por Ji \& Unger (2001), em laboratório, e por Bragagnolo \& Mielniczuk (1990), com base em medições da umidade volumétrica do solo no campo.

A tendência e a magnitude das alterações na evaporação em solos submetidos a plantio direto e preparo convencional necessitam maiores estudos, pela importância que esse processo tem na perda de água em áreas de cultivo. Quantificar a evaporação também é importante para o ajuste de índices e modelos aplicados ao sistema plantio direto.

Este trabalho teve por objetivo quantificar alterações na evaporação da água na superfície do solo em plantio direto, em comparação ao preparo convencional, e avaliar a eficiência do método de microlisímetros de pesagem para medir a evaporação da água na superfície do solo.

\section{Material e Métodos}

Foram conduzidos, em campo, dois experimentos no verão de 2001/2002, dois no verão 2002/2003 e um no verão de 2004/2005, em Eldorado do Sul, Rio Grande do $\mathrm{Sul}\left(30^{\circ} 05^{\prime} \mathrm{S}, 51^{\circ} 39^{\prime} \mathrm{W}, 40 \mathrm{~m}\right.$ de altitude). O clima da região é subtropical úmido do tipo Cfa, conforme Köeppen. A temperatura média mensal do ar é de $25^{\circ} \mathrm{C}$, em janeiro e fevereiro, e $9^{\circ} \mathrm{C}$, em junho e julho (Bergamaschi et al., 2003). O solo da área experimental é um Argissolo Vermelho Distrófico típico, com horizonte B textural e granulometria composta por 49,22 e $29 \%$ de areia, silte e argila, respectivamente, em plantio direto, e 42, 27 e $31 \%$, em preparo convencional (Rojas, 1998).

O delineamento utilizado, em todos os experimentos, foi o inteiramente casualizado, com quatro repetições. Nos verões de 2001/2002 e $2002 / 2003$, foi conduzido um experimento irrigado e outro não irrigado. Os tratamentos utilizados foram os mesmos em todos os experimentos e foram 
constituídos por plantio direto, preparo convencional e cobertura do solo(CP) ou não(SP) com plantas de milho. Os sistemas de manejo do solo estavam implantados desde o inverno de 1995 e, em sua implantação, foram cultivados milho no verão e uma mistura de aveia (Avena strigosa) e ervilhaca (Vicia sativa) no inverno, para a cobertura do solo, com rendimento aproximado de sete toneladas anuais de matéria seca.

Nos experimentos de 2001/2002 e 2002/2003, a semeadura do milho híbrido Pioneer 32R21 foi realizada em 16/11 e 25/11, respectivamente, no espaçamento de $70 \mathrm{~cm}$ entre linhas, totalizando 65.000 plantas ha-1 ${ }^{-1}$ A adubação, o controle de plantas invasoras, de pragas e doenças foi feito conforme indicações para a cultura.

No verão de 2001/2002, foram selecionados sete períodos de medição da evaporação da água do solo nos experimento sem irrigação e dois no com irrigação. No verão de 2002/2003, foram selecionados três períodos no experimento sem irrigação e dois no com irrigação (Tabela 1). Os períodos de medição foram iniciados após a ocorrência de precipitação pluvial igual ou superior a $15 \mathrm{~mm}$ ou após irrigação, e encerrados com o próximo evento de precipitação ou irrigação.

A evaporação da água na superfície do solo, em todos os experimentos, foi medida com microlisímetros de PVC, com $0,15 \mathrm{~m}$ de diâmetro e $0,15 \mathrm{~m}$ de altura, semelhantes aos utilizados por Boast \& Robertson (1982). Os microlisímetros foram totalmente inseridos no solo, por percussão, e depois retirados com o monolito formado no seu interior, mantendo as características da superfície. Na base dos microlisímetros, foi colocada uma tela de nylon, com malha fina, para impedir a perda de solo e facilitar a drenagem da água. A tela foi presa na face externa com fita adesiva de plástico. Após a montagem, os microlisímetros foram repostos nos mesmos locais em que foram retirados, de maneira que a borda desses instrumentos ficasse ao nível da superfície do solo.

Os microlisímetros foram instalados a $0,15 \mathrm{~m}$ de distância das linhas de plantio, no caso do tratamento com plantas; enquanto no tratamento sem plantas, foram instalados ao acaso, em ambos os sistemas de manejo do solo. Foram utilizados os mesmos monolitos de solo durante todo o período das medições de cada experimento e, após o término do período, foi

Tabela 1. Períodos de medição da evaporação da água do solo, número de dias avaliados (ND), lâmina de precipitação (P) ou irrigação (IRRI) aplicada antes do início das medições, número de dias do início de cada período de medição até o início efetivo da medição da evaporação (DIM), índice de área foliar (IAF), temperatura média do ar (Tm) e radiação solar global média $(\mathrm{Rg})$, em experimentos sem irrigação e com irrigação.

\begin{tabular}{|c|c|c|c|c|c|c|}
\hline Período de medição & ND & $\begin{array}{c}\text { P ou IRRI } \\
(\mathrm{mm})\end{array}$ & DIM & $\begin{array}{c}\text { IAF } \\
\left(\mathrm{m}^{2} \mathrm{~m}^{-2}\right)\end{array}$ & $\begin{array}{l}\mathrm{Tm} \\
\left({ }^{\circ} \mathrm{C}\right)\end{array}$ & $\begin{array}{c}\mathrm{Rg} \\
\left(\mathrm{cal} \mathrm{cm}^{-2} \mathrm{dia}^{-1}\right)\end{array}$ \\
\hline & \multicolumn{6}{|c|}{ Com irrigação (verão 2001/2002) } \\
\hline 7 a $19 / 12 / 2001$ & 13 & 29 & 1 & 0,21 & 21,9 & 453 \\
\hline 23 a $29 / 12 / 2001$ & 07 & 35 & 2 & 2,08 & 21,8 & 596 \\
\hline 2 a $4 / 1 / 2002$ & 03 & 28 & 2 & 3,83 & 23,9 & 608 \\
\hline 9 a $20 / 1 / 2002$ & 12 & 44 & 4 & 4,31 & 23,5 & 587 \\
\hline 26 a $29 / 01 / 2002$ & 04 & 39 & 2 & 4,50 & 23,8 & 347 \\
\hline 2 a 4/2/2002 & 03 & 19 & 2 & 4,51 & 21,1 & 575 \\
\hline \multirow[t]{2}{*}{14 a 26/2/2002 } & 13 & 37 & 2 & 4,51 & 22,6 & 468 \\
\hline & \multicolumn{6}{|c|}{ Com irrigação (verão 2002/2003) } \\
\hline $26 / 12 / 2002$ a $9 / 1 / 2003$ & 15 & 37 & 3 & 1,39 & 24,3 & 531 \\
\hline 13 a $16 / 1 / 2003$ & 04 & 17 & 3 & 4,26 & 24,9 & 639 \\
\hline \multirow[t]{2}{*}{$24 / 1$ a 4/2/2003 } & 12 & 46 & 1 & 4,48 & 25,2 & 611 \\
\hline & \multicolumn{6}{|c|}{ Sem irrigação (verão 2001/2002) } \\
\hline 18 a $19 / 12 / 2001$ & 02 & 17 & 1 & 1,14 & 22,6 & 567 \\
\hline \multirow[t]{2}{*}{16 a $17 / 1 / 2002$} & 02 & 33 & 2 & 4,46 & 21,2 & 638 \\
\hline & \multicolumn{6}{|c|}{ Sem irrigação (verão 2002/2003) } \\
\hline 8 a $9 / 1 / 2003$ & 02 & 28 & 1 & 3,92 & 24,7 & 551 \\
\hline $29 / 1$ a $2 / 2 / 2003$ & 05 & 25 & 1 & 4,50 & 26,5 & 629 \\
\hline
\end{tabular}

Pesq. agropec. bras., Brasília, v.45, n.8, p.780-790, ago. 2010 
determinada a densidade do solo seco, pela relação entre a massa e o volume de solo de cada microlisímetro. A umidade volumétrica foi calculada no primeiro dia de cada período de medição, multiplicando-se a umidade gravimétrica pela densidade do solo. A umidade gravimétrica foi obtida pela diferença de massa entre dois dias consecutivos de medição.

A evaporação da água do solo $(\mathrm{mm})$ foi obtida pela diferença de massa dos microlisímetros, em uma balança eletrônica com resolução de $2 \mathrm{~g}$ ou $0,1 \mathrm{~mm}$, na frequência diária ou, no máximo, a cada três dias, próximo das 9 horas. A diferença entre os dias $n$ e $n+1$ representou a evaporação do dia $n$. Os dados relativos ao número de dias em que a evaporação foi medida, à lâmina de precipitação pluvial ocorrida ou irrigação aplicada, ao número de dias do início de cada período de medição até o início efetivo da medição, ao índice de área foliar, à temperatura média do ar e à radiação solar global média, em cada período de medição, encontram-se na Tabela 1. A temperatura média do ar e a radiação solar global foram medidas na estação meteorológica automática, próximo à área experimental, e o índice de área foliar do milho foi obtido de Dalmago (2004).

Nos experimentos irrigados, a irrigação foi feita com sistema de aspersores em linha, espaçados em $6 \mathrm{~m}$. O manejo da irrigação baseou-se na variação do potencial matricial da água no solo, monitorado com conjuntos de tensiômetros com manômetro de mercúrio, instalados nas profundidades de 7,5, 15, $30,45,60,75$ e $90 \mathrm{~cm}$, nos tratamentos em plantio direto. A lâmina aplicada foi calculada de acordo com a evapotranspiração máxima da cultura, medida em lisímetro de pesagem instalado em área adjacente, cultivada com milho, nas mesmas condições da área experimental. As irrigações foram iniciadas quando o potencial matricial da água do solo atingiu o valor de -0,03 MPa no tensiômetro instalado a $30 \mathrm{~cm}$ de profundidade. A lâmina de água aplicada antes do início de cada período de medição da evaporação encontra-se na Tabela 1.

O experimento do verão de 2004/2005 foi conduzido com a finalidade de avaliar a metodologia de medição da evaporação da água do solo por microlisímetros. Para isso, comparou-se a evaporação medida com os microlisímetros instalados no interior de um lisímetro de pesagem com $5,1 \mathrm{~m}^{2}$ de área, instalado no centro de uma área de 0,5 ha cultivada com milho, com a evaporação medida pelo lisímetro de pesagem descrito em Santos et al. (2000). O milho híbrido simples Pioneer 32R21 foi semeado em 17/11/2004, com espaçamento de $0,80 \mathrm{~m}$ entre linhas e população entre 85.000 e 90.000 plantas ha $^{-1}$, seguindo-se as indicações técnicas para a cultura.

A evaporação da água do solo foi medida com cinco microlisímetros idênticos àqueles utilizados nos verões de 2001/2002 e 2002/2003, instalados a $15 \mathrm{~cm}$ de distância da linha de plantas, no interior do lisímetro. A evaporação foi obtida por diferença de massa entre duas pesagens consecutivas. A evaporação medida pelo lisímetro foi obtida pela diferença entre a evapotranspiração da cultura e a transpiração de plantas de milho na área do lisímetro, no mesmo período de medição da evaporação da água do solo com microlisímetro. A evapotranspiração da cultura foi medida por diferença de massas no lisímetro de pesagem (Santos et al., 2000), e a transpiração foi medida por um sistema de pulso de calor também descrito por Santos et al. (2000). As medições da evaporação e da evapotranspiração da cultura foram realizadas diariamente, ou no máximo a cada três dias, próximo das $9 \mathrm{~h}$, tendo reiniciado após cada precipitação pluvial ou irrigação. Todas as medições foram feitas entre 6/1/2005 a 2/2/2005.

As evaporações medidas com microlisímetros e com o lisímetro de pesagem foram comparadas por análise de regressão, tendo-se considerado valores diários ou acumulados, conforme o caso. Nos experimentos dos verões de 2001/2002 e 2002/2003, os tratamentos foram avaliados por meio da análise da variância e pela análise de correlação de Pearson, e as médias comparadas pelo teste de Tukey ou teste t, a 5\% de probabilidade.

\section{Resultados e Discussão}

A evaporação da água do solo dos experimentos sem irrigação, na maior parte dos períodos de medição, não apresentou interação significativa entre tratamentos (Tabela 2). Dos três períodos de medição em que houve interação, dois foram relativos aos primeiros períodos de medição de cada experimento, provavelmente em razão das medições terem iniciado logo após a instalação dos microlisímetros, quando o solo no interior desses instrumentos e o ambiente externo ainda não haviam se consolidado. 
Nesses experimentos sem irrigação, em todos os períodos de medição com interação, as diferenças de evaporação entre sistemas de manejo de solo ocorreram apenas no tratamento sem plantas (Tabela 2). Neste caso, a evaporação acumulada sempre foi maior no solo sob plantio direto, quando comparado ao preparo convencional, especialmente após a precipitação pluvial, já que a umidade volumétrica (Tabela 2), no plantio direto, foi mais elevada no primeiro dia de medição em praticamente todos os períodos de avaliação. Já a falta de diferenças significativas entre plantio direto e preparo convencional, no tratamento com plantas, indica que as plantas de milho mascararam os efeitos dos sistemas de manejo sobre a evaporação da água do solo.

Nos períodos de medição dos experimentos sem irrigação em que não houve interação entre tratamentos, a evaporação da água do solo também foi maior em solo sob plantio direto, em dois dos períodos de medição, comparado ao solo sob preparo convencional, e em um período de medição a resposta foi contrária (Tabela 2). Já nos tratamentos com cobertura de solo, a evaporação foi significativamente maior no tratamento sem plantas, em um período de medição de cada experimento. Nos demais períodos de medição, não houve diferença significativa entre os tratamentos. As diferenças de evaporação da água do solo entre os sistemas de manejo de solo podem ser atribuídas, principalmente, aos maiores teores de umidade volumétrica em solo sob plantio direto (Tabela 3 e 4) que, consequentemente, proporcionaram maiores valores de evaporação nesse tratamento. No tratamento sem plantas, a evaporação foi mais elevada em alguns períodos, em relação ao tratamento com plantas, mesmo com menor umidade do solo no interior dos microlisímetros. Isso pode ser atribuído à maior quantidade de energia que chega na superfície do solo no tratamento sem plantas, em relação ao tratamento com plantas, no qual o dossel intercepta grande parte da radiação solar incidente (Tahiri et al., 2006; Kunz et al., 2007). As respostas observadas para evaporação acumulada da água do solo foram consistentes, tanto para períodos de medição longos, de 15 dias, quanto curtos, de 5 dias.

$\mathrm{Na}$ maioria dos períodos de medição em que houve diferenças significativas entre os sistemas de manejo do solo, a evaporação da água do solo foi maior em plantio

Tabela 2. Evaporação acumulada da água do solo ( $\mathrm{mm}$ ) em plantio direto (PD) e preparo convencional (PC), em áreas com plantas (CP) e sem plantas (SP), com e sem irrigação, nos diversos períodos de medição, em experimentos que apresentaram ou não interação significativa entre os tratamentos ${ }^{(1)}$.

\begin{tabular}{|c|c|c|c|c|c|c|c|c|}
\hline \multirow[t]{3}{*}{ Período de medição } & \multicolumn{4}{|c|}{ Interação significativa } & \multicolumn{4}{|c|}{ Sem interação } \\
\hline & \multicolumn{2}{|c|}{$\mathrm{CP}$} & \multicolumn{2}{|c|}{ SP } & \multicolumn{2}{|c|}{ Manejo do solo } & \multicolumn{2}{|c|}{ Planta } \\
\hline & $\mathrm{PD}$ & $\mathrm{PC}$ & $\mathrm{PD}$ & $\mathrm{PC}$ & $\mathrm{PD}$ & $\mathrm{PC}$ & $\mathrm{CP}$ & SP \\
\hline & \multicolumn{8}{|c|}{ Sem irrigação (verão 2001/2002) } \\
\hline 07 a $19 / 12 / 2001$ & $19,5 \mathrm{a}$ & $20,0 \mathrm{a}$ & $020,5 \mathrm{a}$ & $18,5 b$ & - & - & - & - \\
\hline 23 a $29 / 12 / 2001$ & - & - & - & - & $13,5 b$ & $14,8 \mathrm{a}$ & $13,8 \mathrm{a}$ & $14,6 \mathrm{a}$ \\
\hline 2 a $4 / 1 / 2002$ & - & - & - & - & $05,1 \mathrm{a}$ & $05,7 \mathrm{a}$ & $04,9 \mathrm{a}$ & $05,9 \mathrm{a}$ \\
\hline 9 a $20 / 1 / 2002$ & - & - & - & - & $10,9 \mathrm{a}$ & $09,4 b$ & $10,1 \mathrm{a}$ & $10,2 \mathrm{a}$ \\
\hline 26 a $29 / 1 / 2002$ & - & - & - & - & $11,0 \mathrm{a}$ & $10,4 \mathrm{a}$ & $07,2 b$ & $14,2 \mathrm{a}$ \\
\hline 2 a 4/2/2002 & $03,4 \mathrm{a}$ & $04,5 \mathrm{a}$ & $004,7 \mathrm{a}$ & $03,6 b$ & - & - & - & - \\
\hline \multirow{2}{*}{14 a $26 / 2 / 2002$} & - & - & - & - & $13,2 \mathrm{a}$ & $13,3 \mathrm{a}$ & $13,0 \mathrm{a}$ & $13,6 \mathrm{a}$ \\
\hline & \multicolumn{8}{|c|}{ Sem irrigação (verão 2002/2003) } \\
\hline $26 / 12 / 2002$ a $9 / 1 / 2003$ & $17,1 \mathrm{a}$ & $18,0 \mathrm{a}$ & $017,7 \mathrm{a}$ & $15,1 \mathrm{~b}$ & - & - & - & - \\
\hline 13 a $16 / 1 / 2003$ & - & - & - & - & $05,2 \mathrm{a}$ & $03,8 b$ & $04,0 \mathrm{~b}$ & $05,1 \mathrm{a}$ \\
\hline \multirow[t]{2}{*}{$24 / 1$ a $4 / 2 / 2003$} & - & - & - & - & $17,5 \mathrm{a}$ & $16,6 \mathrm{a}$ & $16,6 \mathrm{a}$ & $17,7 \mathrm{a}$ \\
\hline & \multicolumn{8}{|c|}{ Com irrigação (verão 2001/2002) } \\
\hline 18 a $19 / 12 / 2001$ & - & - & - & - & $4,5 b$ & $05,9 \mathrm{a}$ & $5,8 \mathrm{a}$ & $04,6 \mathrm{~b}$ \\
\hline \multirow[t]{2}{*}{16 a $17 / 1 / 2002$} & - & - & - & - & $2,2 \mathrm{a}$ & $02,0 \mathrm{a}$ & $2,3 \mathrm{a}$ & $01,8 \mathrm{~b}$ \\
\hline & \multicolumn{8}{|c|}{ Com irrigação (verão 2002/2003) } \\
\hline 8 a $9 / 1 / 2003$ & $02,6 a$ & $01,6 b$ & $02,2 \mathrm{a}$ & $02,4 a$ & - & - & - & - \\
\hline $29 / 1$ a $2 / 2 / 2003$ & $04,5 b$ & $09,3 \mathrm{a}$ & $08,5 \mathrm{a}$ & $08,9 \mathrm{a}$ & - & - & - & - \\
\hline
\end{tabular}

${ }^{(1)}$ Médias seguidas de letras iguais nas linhas não diferem entre si pelo teste de Tukey, a 5\% de probabilidade, em cada tratamento (CP e SP) da interação significativa, e em cada tratamento (Manejo do solo e Planta) da interação não significativa. 
direto do que no preparo convencional (Tabela 2), o que contraria medições pontuais feitas na maior parte dos trabalhos realizados sobre o tema, que indicam uma evaporação mais elevada em solo sob preparo convencional, ou semelhante à ocorrida em solo sob plantio direto (Fabrizzi, et al. 2005; Moret et al., 2006; De Vita et al., 2007). Porém, é importante observar que a evaporação e a redistribuição da água no interior do solo são processos simultâneos e apresentam diferenças de solo para solo (Yang \& Yanful, 2002), e a dinâmica desses processos pode ser alterada pela variação na quantidade de palha em superfície, entre outros fatores (Ji \& Unger, 2001).

Nos experimentos com irrigação, houve interação entre os tratamentos nos dois períodos de medição de 2002/2003, mas não nos dois períodos de 2001/2002
(Tabela 2). Nos períodos de medição de 2002/2003, quando a interação foi significativa, em um dos períodos de medição a evaporação foi menor em solo sob preparo convencional e, no outro, foi menor em plantio direto, no solo com plantas, enquanto no solo sem plantas, não houve diferenças entre os sistemas de manejo do solo. Nos períodos de medição de 2001/2002, em que não houve interação entre os tratamentos, o solo em preparo convencional apresentou evaporação igual ou superior à observada em solo sob plantio direto. Isso foi observado, apesar do solo em plantio direto nos microlisímetros ter apresentado, em geral, maior umidade no início das medições do que o solo em preparo convencional (Tabela 3). Por sua vez, nesses mesmos períodos de medição, a evaporação foi maior

Tabela 3. Densidade média do solo (Ds) e umidade volumétrica do solo (Uv) no interior dos microlisímetros, nos tratamentos plantio direto (PD) e preparo convencional (PC), com plantas (CP) e sem plantas (SP), no primeiro dia de medição da evaporação da água do solo, nos diversos períodos de medição, com e sem irrigação, nos experimentos que apresentaram ou não interação significativa entre os tratamentos ${ }^{(1)}$.

\begin{tabular}{|c|c|c|c|c|c|c|c|c|}
\hline \multirow[t]{3}{*}{ Período de medição } & \multicolumn{4}{|c|}{ Interação significativa } & \multicolumn{4}{|c|}{ Sem interação } \\
\hline & \multicolumn{2}{|c|}{$\mathrm{CP}$} & \multicolumn{2}{|c|}{ SP } & \multicolumn{2}{|c|}{ Manejo do solo } & \multicolumn{2}{|c|}{ Planta } \\
\hline & PD & $\mathrm{PC}$ & $\mathrm{PD}$ & $\mathrm{PC}$ & $\mathrm{PD}$ & $\mathrm{PC}$ & $\mathrm{CP}$ & SP \\
\hline & \multicolumn{8}{|c|}{ Sem irrigação (verão 2001/2002) } \\
\hline Ds média $\left(\mathrm{Mg} \mathrm{m}^{-3}\right)$ & 1,50 & 1,56 & 1,34 & 1,48 & 1,42 & 1,52 & 1,53 & 1,41 \\
\hline \multicolumn{9}{|l|}{$\mathrm{Uv}\left(\mathrm{cm}^{3} \mathrm{~cm}^{-3}\right)$} \\
\hline 7 a $19 / 12 / 2001$ & - & - & - & - & $0,280 \mathrm{a}$ & $0,273 b$ & $0,284 \mathrm{a}$ & $0,269 \mathrm{a}$ \\
\hline 23 a 29/12/2001 & - & - & - & - & $0,256 a$ & $0,262 \mathrm{a}$ & $0,259 \mathrm{a}$ & $0,259 \mathrm{a}$ \\
\hline 2 a $4 / 1 / 2002$ & - & - & - & - & $0,209 \mathrm{a}$ & $0,212 \mathrm{a}$ & $0,208 \mathrm{a}$ & $0,213 \mathrm{a}$ \\
\hline 9 a $20 / 1 / 2002$ & - & - & - & - & $0,198 \mathrm{a}$ & $0,196 b$ & $0,205 a$ & $0,188 \mathrm{a}$ \\
\hline 26 a $29 / 1 / 2002$ & - & - & - & - & $0,232 b$ & $0,273 \mathrm{a}$ & $0,267 \mathrm{a}$ & $0,238 b$ \\
\hline 2 a 4/02/2002 & - & - & - & - & $0,208 \mathrm{a}$ & $0,211 \mathrm{a}$ & $0,207 a$ & $0,212 \mathrm{a}$ \\
\hline \multirow[t]{2}{*}{14 a $26 / 2 / 2002$} & - & - & - & - & $0,226 \mathrm{a}$ & $0,227 \mathrm{a}$ & $0,227 \mathrm{a}$ & $0,226 \mathrm{a}$ \\
\hline & \multicolumn{8}{|c|}{ Sem irrigação (verão 2002/2003) } \\
\hline Ds média $\left(\mathrm{Mg} \mathrm{m}^{-3}\right)$ & 1,53 & 1,56 & 1,41 & 1,46 & 1,55 & 1,44 & 1,47 & 1,51 \\
\hline \multicolumn{9}{|l|}{$\mathrm{Uv}\left(\mathrm{cm}^{3} \mathrm{~cm}^{-3}\right)$} \\
\hline $26 / 12 / 2$ a $9 / 1 / 2003$ & - & - & - & - & $0,293 \mathrm{a}$ & $0,225 b$ & $0,277 \mathrm{a}$ & $0,241 b$ \\
\hline 13 a $16 / 1 / 2003$ & - & - & - & - & $0,202 \mathrm{a}$ & $0,178 b$ & $0,216 \mathrm{a}$ & $0,165 b$ \\
\hline \multirow[t]{2}{*}{$24 / 1$ a 4/2/2003 } & - & - & - & - & $0,252 \mathrm{a}$ & $0,232 b$ & $0,262 \mathrm{a}$ & $0,221 b$ \\
\hline & \multicolumn{8}{|c|}{ Com irrigação (verão 2001/2002) } \\
\hline Ds média $\left(\mathrm{Mg} \mathrm{m}^{-3}\right)$ & 1,50 & 1,59 & 1,31 & 1,45 & 1,55 & 1,38 & 1,41 & 1,52 \\
\hline \multicolumn{9}{|l|}{$\mathrm{Uv}\left(\mathrm{cm}^{3} \mathrm{~cm}^{-3}\right)$} \\
\hline 18 a $19 / 12 / 2001$ & - & - & - & - & $0,235 \mathrm{a}$ & $0,196 b$ & $0,235 \mathrm{a}$ & $0,195 b$ \\
\hline \multirow[t]{2}{*}{16 a $17 / 1 / 2002$} & - & - & - & - & $0,205 \mathrm{a}$ & $0,193 b$ & $0,218 \mathrm{a}$ & $0,180 \mathrm{a}$ \\
\hline & \multicolumn{8}{|c|}{ Com irrigação (verão 2002/2003) } \\
\hline Ds média $\left(\mathrm{Mg} \mathrm{m}^{-3}\right)$ & 1,49 & 1,54 & 1,37 & 1,53 & 1,53 & 1,45 & 1,43 & 1,54 \\
\hline \multicolumn{9}{|l|}{$\mathrm{Uv}\left(\mathrm{cm}^{3} \mathrm{~cm}^{-3}\right)$} \\
\hline 8 a $9 / 1 / 2003$ & $0,265 \mathrm{a}$ & $0,174 b$ & $0,180 \mathrm{a}$ & $0,154 \mathrm{a}$ & - & - & - & - \\
\hline $29 / 1$ a $2 / 2 / 2003$ & - & - & - & - & $0,286 \mathrm{a}$ & $0,230 \mathrm{a}$ & $0,267 \mathrm{a}$ & $0,248 b$ \\
\hline
\end{tabular}


no tratamento com plantas, em relação ao sem plantas. Em parte, essa resposta pode ser atribuída ao maior teor de umidade no solo interno aos microlisímetros no tratamento com plantas. Ainda no tratamento com plantas, o solo seca mais lentamente na superfície, em comparação ao tratamento sem plantas. Esse fato mantém inalteradas as taxas de evaporação da água do solo, no tratamento com plantas, mas pode restringir essas taxas no tratamento sem plantas, com a secagem da camada de solo superficial (Lemon, 1956).

Outros fatores também podem interferir significativamente na evaporação, nos experimentos com irrigação. A irrigação por aspersão, por não apresentar a mesma homogeneidade de distribuição de água que a precipitação pluvial (Rodrigues et al., 2001), pode aumentar a variabilidade da umidade do solo no interior dos microlisímetros. Além disso, a demanda hídrica atmosférica após a irrigação é diferente daquela encontrada após precipitação pluvial, o que resulta em respostas diferenciadas de evaporação. É provável, também, que as respostas dos experimentos com irrigação estejam relacionadas aos períodos mais curtos de medição, em relação aos realizados nos experimentos sem irrigação.

A análise de correlação entre a evaporação da água do solo e um grupo de sete variáveis apontou correlação positiva com as seguintes variáveis, em praticamente todos os tratamentos dos experimentos sem irrigação (Tabela 4): número de dias de medição, precipitação pluvial ocorrida antes do início das medições, e umidade volumétrica no interior dos microlisímetros, no primeiro dia de medição. Esses resultados são coerentes, já que mais água disponível, num tempo maior de exposição às condições de demanda hídrica atmosférica, deve resultar em maior evaporação, se houver energia para o processo acontecer. A variabilidade da evaporação como função do tempo de medição e da precipitação pluvial antes do início do período de medições foi apontada também por Aydin et al. (2005), Moret et al. (2006) e Yuan et al. (2009). Contudo, foi encontrada correlação negativa entre evaporação da água do solo e índice de área foliar em ambos os sistemas de manejo do solo. Provavelmente, esse resultado se deve ao sombreamento causado pelo dossel, que reduz a energia incidente na superfície do solo (Tahiri et al., 2006; Kunz et al., 2007). De acordo com Ward et al. (2009), a evaporação acumulada não apresenta correlação significativa com a temperatura média do ar e com a radiação solar global média de períodos de medição.

Nos experimentos com irrigação, a evaporação da água do solo praticamente não apresentou correlação significativa com as variáveis analisadas (Tabela 4). A tendência observada pode ser atribuída ao baixo número de períodos de medição e ao baixo número de dias em que a evaporação foi medida em cada período, nesses experimentos (Tabela 1), bem como ao efeito da irrigação, que tende a uniformizar as diferenças entre tratamentos e a mascarar as relações da evaporação da água do solo com outras variáveis.

A evaporação da água do solo, nos experimentos sem irrigação, inicialmente foi mais elevada em preparo convencional, independentemente da presença de plantas, em grande parte dos períodos de medição (Figura 1). Porém, a taxa de evaporação se inverteu entre dois e cinco dias após a precipitação pluvial, quando houve tendência para que a evaporação passasse a ser mais elevada em plantio direto, independentemente da presença de plantas. No experimento com irrigação, no entanto, essa variação somente foi evidente nos tratamentos sem plantas (Figura 2).

No início das medições, a evaporação da água do solo ocorre sem restrição (estágio 1), se houver disponibilidade de energia para que ocorra (Lemon, 1956), e ela será mais elevada em solos com maior teor de umidade na superfície. Todavia, o solo em preparo convencional apresentou maior evaporação, no início das medições, nos experimentos sem irrigação (Figura 1), mesmo tendo apresentado menor umidade volumétrica inicial, na maioria das vezes em que esse parâmetro diferiu significativamente entre os sistemas de manejo (Tabela 3).

A inversão da taxa de evaporação observada entre os sistemas de manejo, entre dois e cinco dias após o início das medições, pode ser explicada pela secagem mais rápida da camada superficial do solo em preparo convencional, em comparação ao plantio direto. Com a secagem da camada superficial do solo, a evaporação passa para o estágio 2 (Lemon, 1956), em que ocorre com menor intensidade, em razão da condutividade hidráulica não saturada do solo diminuir à medida em que o solo seca (Aydin et al., 2005). No solo em plantio direto, a evaporação, provavelmente, se manteve no estágio 1 por mais tempo (Lemon, 1956), uma vez que este solo apresenta maior retenção de água próximo à superfície, quando comparado ao solo sob preparo convencional (Dalmago et al., 2009; Martorano 

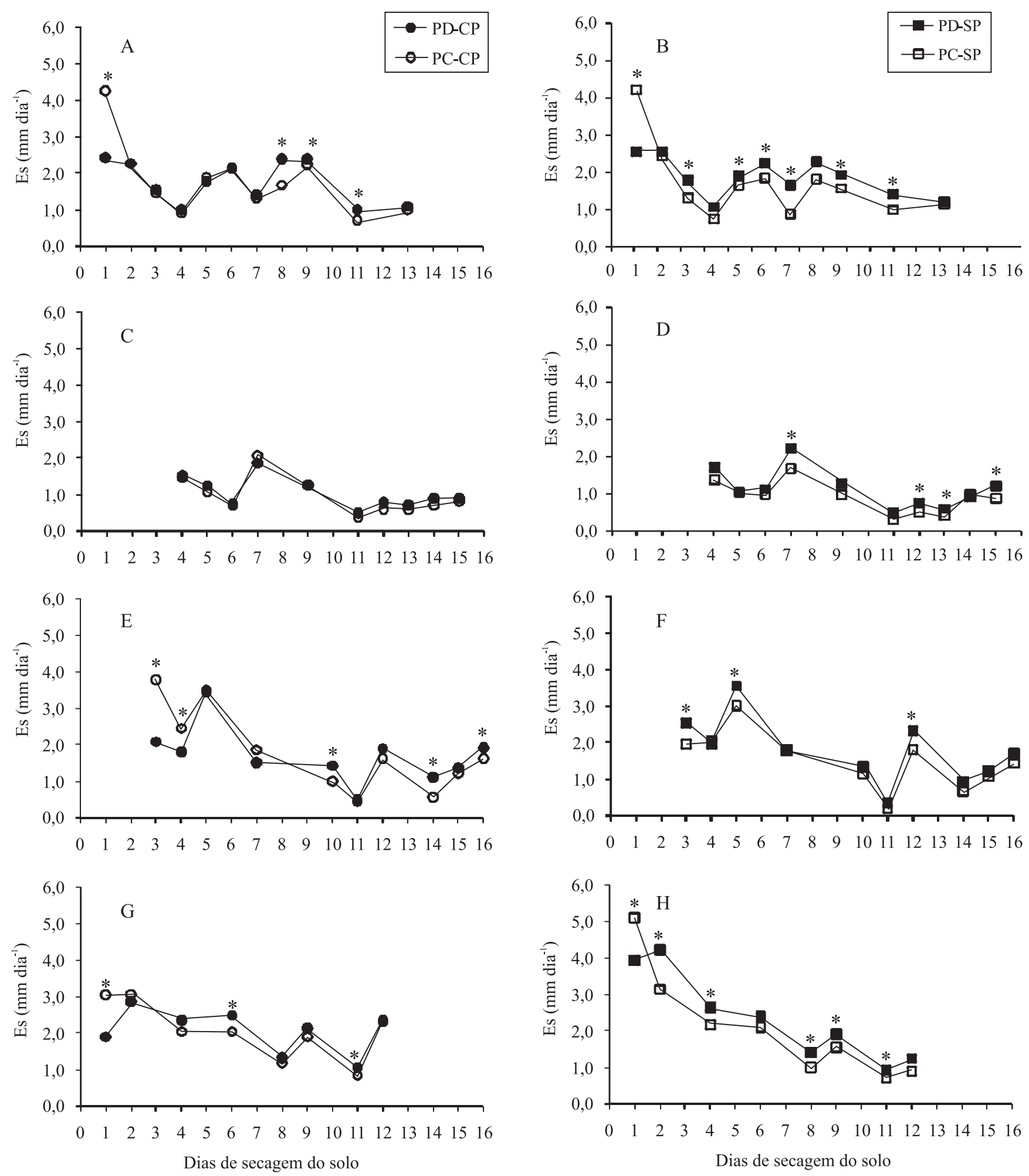

Figura 1. Evaporação da água do solo (Es), em função do número de dias após o início do período de medição (dias de secagem do solo), em solo sob plantio direto (PD) e preparo convencional (PC) com (CP) e sem (SP) plantas de milho crescendo sobre ele (figuras da direita e esquerda, respectivamente), em diferentes períodos de medição, em experimentos sem irrigação. Períodos de medição: A e B, 07/12/2001 a 19/12/2001; C e D, 09/01/2002 a 20/01/2002; E e F, 26/12/2002 a 09/01/2003; G e H, 24/01/2003 a 04/02/2003, respectivamente. *Significativo a 5\% de probabilidade de erro, pelo teste t. 
et al., 2009; Yuan et al., 2009). Ji \& Unger (2001) encontraram maior evaporação em solo com palhada e atribuíram-na ao maior teor de umidade neste solo.

A palha na superfície do solo em plantio direto é outro fator que retarda a secagem do solo, e mantém por mais tempo a evaporação no estágio 1 (Lemon, 1956). A palha também impede o impacto direto da água da chuva no solo, o que evita a formação do selamento superficial (Barcelos et al., 1999), que

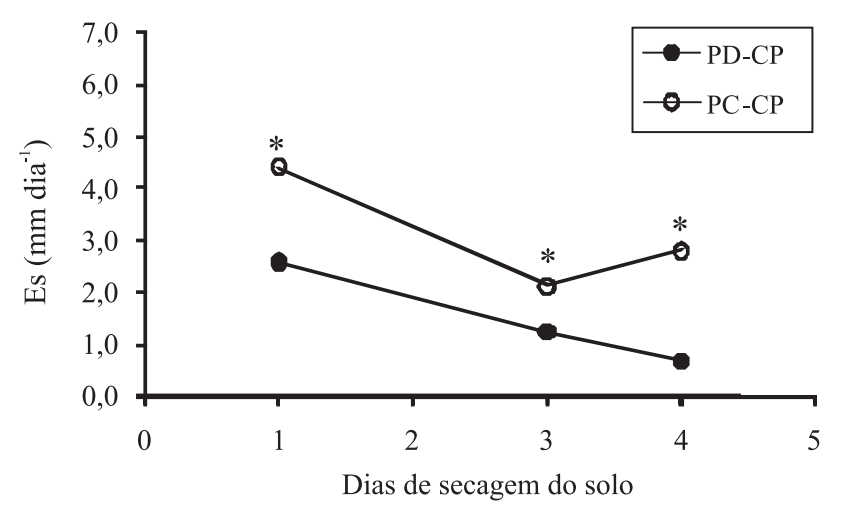

auxilia na formação de uma camada de solo mais seca, próximo à superfície. A camada seca quebra a continuidade dos poros com o restante do perfil do solo (Aydin et al., 2005), o que praticamente não ocorre em solo sob plantio direto, onde a continuidade porosa e a condutividade de água do interior do perfil para a superfície é mantida (Moitra et al., 1996).

$\mathrm{Na}$ avaliação da representatividade da técnica dos microlisímetros para medição direta da evaporação da

Figura 2. Evaporação da água do solo (Es), em função do número de dias após o início do período de medição (dias de secagem do solo), em solo sob plantio direto (PD) e preparo convencional (PC) com (CP) e sem (SP) plantas de milho crescendo sobre ele (figuras da direita e esquerda, respectivamente), em experimentos com uso de irrigação, no período de 29/01/2003 a 02/02/2003. *Significativo a 5\% de probabilidade de erro pelo teste $t$.

Tabela 4. Coeficiente e correlação de Pearson entre a evaporação acumulada da água do solo e diferentes variáveis relacionadas a ela, nos tratamentos de manejo de solo em plantio direto (PD), preparo convencional (PC), com plantas (CP) e sem plantas (SP), nos experimentos com irrigação e sem irrigação.

\begin{tabular}{|c|c|c|c|c|}
\hline \multirow[t]{2}{*}{ Variável $^{(1)}$} & \multicolumn{2}{|c|}{ Manejo do solo } & \multicolumn{2}{|c|}{ Plantas } \\
\hline & $\mathrm{PD}$ & $\mathrm{PC}$ & $\mathrm{CP}$ & SP \\
\hline & \multicolumn{4}{|c|}{ Sem irrigação (verões 2001/2002 e 2002/2003) } \\
\hline $\mathrm{ND}\left(\mathrm{n}^{\mathrm{o}}\right)$ & $0,84 * *$ & $0,80 * *$ & $0,87 * *$ & $0,74 * *$ \\
\hline $\mathrm{P}(\mathrm{mm})$ & $0,62 *$ & $0,61 *$ & $0,55^{*}$ & $0,66^{* *}$ \\
\hline $\operatorname{DIM}\left(\mathrm{n}^{\mathrm{o}}\right)$ & $-0,36^{\mathrm{ns}}$ & $-0,42^{\mathrm{ns}}$ & $-0,34^{\mathrm{ns}}$ & $-0,43^{\mathrm{ns}}$ \\
\hline $\operatorname{IAF}\left(\mathrm{m}^{2} \mathrm{~m}^{-2}\right)$ & $-0,63 * *$ & $-0,66^{* *}$ & - & - \\
\hline $\operatorname{Tm}\left({ }^{\circ} \mathrm{C}\right)$ & $0,04^{\mathrm{ns}}$ & $-0,03^{\text {ns }}$ & $-0,03^{\text {ns }}$ & $0,04^{\mathrm{ns}}$ \\
\hline $\operatorname{Rg}\left(\mathrm{cal} \mathrm{cm}{ }^{-2} \mathrm{dia}^{-1}\right)$ & $-0,35^{\text {ns }}$ & $-0,35^{\mathrm{ns}}$ & $0,22^{\mathrm{ns}}$ & $-0,47^{\mathrm{ns}}$ \\
\hline \multirow[t]{2}{*}{$\mathrm{Uv}\left(\mathrm{cm}^{3} \mathrm{~cm}^{-3}\right)$} & $0,86 * *$ & $0,67 * *$ & $0,78 * *$ & $0,75^{* *}$ \\
\hline & \multicolumn{4}{|c|}{ Com irrigação (verões 2001/2002 e 2002/2003) } \\
\hline $\mathrm{ND}\left(\mathrm{n}^{\circ}\right)$ & $0,86^{\mathrm{ns}}$ & $0,84^{\mathrm{ns}}$ & $0,72^{\mathrm{ns}}$ & $0,92 *$ \\
\hline IRRI (mm) & $-0,56^{\text {ns }}$ & $-0,57^{\mathrm{ns}}$ & $-0,70^{\text {ns }}$ & $-0,45^{\mathrm{ns}}$ \\
\hline $\operatorname{DIM}\left(\mathrm{n}^{\mathrm{o}}\right)$ & $-0,56^{\mathrm{ns}}$ & $-0,53^{\text {ns }}$ & $-0,54^{\text {ns }}$ & $-0,54^{\mathrm{ns}}$ \\
\hline $\operatorname{IAF}\left(\mathrm{m}^{2} \mathrm{~m}^{-2}\right)$ & $-0,11^{\mathrm{ns}}$ & $-0,13^{\mathrm{ns}}$ & - & - \\
\hline $\operatorname{Tm}\left({ }^{\circ} \mathrm{C}\right)$ & $0,66^{\mathrm{ns}}$ & $0,62^{\mathrm{ns}}$ & $0,49^{\mathrm{ns}}$ & $0,74^{\mathrm{ns}}$ \\
\hline $\operatorname{Rg}\left(\mathrm{cal} \mathrm{cm}{ }^{-2} \mathrm{dia}^{-1}\right)$ & $0,24^{\mathrm{ns}}$ & $0,26^{\mathrm{ns}}$ & $0,18^{\mathrm{ns}}$ & $0,29^{\mathrm{ns}}$ \\
\hline $\mathrm{Uv}\left(\mathrm{cm}^{3} \mathrm{~cm}^{-3}\right)$ & $0,96 * *$ & $0,89^{\text {ns }}$ & $0,91^{*}$ & $0,97 * *$ \\
\hline
\end{tabular}

${ }^{(1)} \mathrm{ND}$, número de dias em que a evaporação foi medida; P, lâmina de precipitação pluvial ocorrida no início do período de medição; IRRI, lâmina de irrigação aplicada antes do início dos períodos de medição; DIM, número de dias do início de cada período de medição até o início da medição; IAF, índice de área foliar; Tm, temperatura média do ar nos período de medição; Rg, radiação solar global média em cada período de medição; Uv, umidade volumétrica do solo no interior dos microlisímetros no primeiro dia de início de medição. ns Não significativo. *e**Significativo a 5 e $1 \%$ de probabilidade, respectivamente. 
água do solo em campo, no verão de 2004/2005, verificouse que a evaporação medida com microlisímetros apresentou relação direta e significativa coma evaporação da água do solo medida com o lisímetro de pesagem (Figura 3 A). Em termos diários, os microlisímetros mediram evaporação, em média, $11 \%$ superior à medida com o lisímetro de pesagem $\left( \pm 0,3 \mathrm{~mm} \mathrm{dia}^{-1}\right)$. $\mathrm{O}$ elevado coeficiente de determinação observado entre essas medidas demonstra que a técnica dos microlisímetros, utilizada neste trabalho, pode ser adotada para medições da evaporação da água do solo. A adequabilidade dessa técnica fica mais evidente quando a evaporação da água do solo foi acumulada, em diferentes períodos sequenciais de medição (Figura 3 B). Neste caso, o ajuste entre evaporação medida com microlisímetros e com lisímetro de pesagem foi maior do que a evaporação em base diária (Figura $3 \mathrm{~A}$ ). $\mathrm{O}$ ajuste significativo da evaporação medida com os microlisímetros, em relação à medida com lisímetro de pesagem, tanto em termos
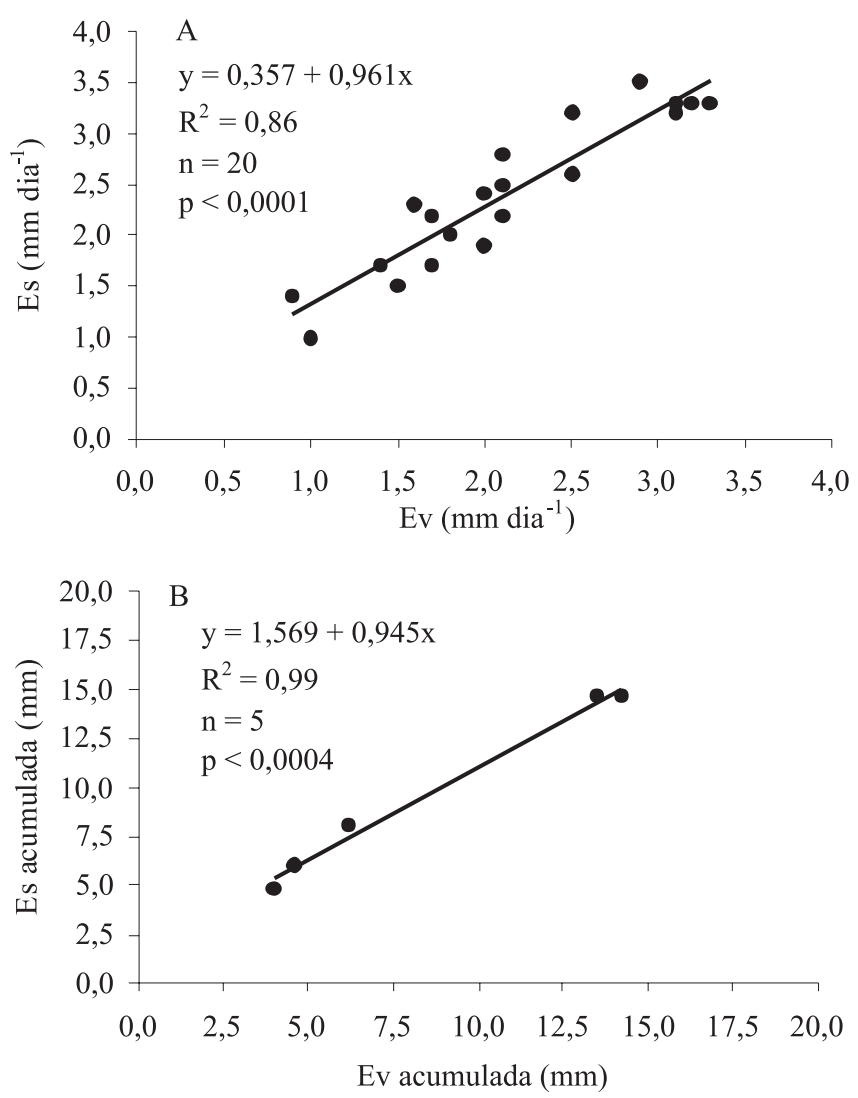

Figura 3. Evaporação da água do solo medida com microlisímetros (Es), e evaporação da água do solo medida com lisímetro de pesagem (Ev). A, evaporação medida diariamente; B, evaporação acumulada em períodos seqüenciais de medição. diários, quanto em termos de evaporação acumulada, indica que os microlisímetros são adequados para medições diretas de valores absolutos de evaporação em campo. Resultados semelhantes foram obtidos por Tahiri et al. (2006), em cultivo de milho e com uso de microlisímetros de tamanho próximo aos utilizados neste trabalho.

\section{Conclusões}

1. Em $90 \%$ dos ciclos de secagem do solo avaliados, a evaporação acumulada da água do solo em plantio direto não difere ou é maior do que a ocorrida no solo em preparo convencional.

2. As diferenças entre as evaporações acumuladas da água do solo em plantio direto e preparo convencional se mantêm em área cultivada com plantas e área sem plantas.

3. A irrigação e a presença de plantas sobre o solo mascaram o efeito dos sistemas de manejo do solo sobre a evaporação acumulada da água do solo.

4. A evaporação da água do solo é maior sob preparo convencional, logo após precipitações pluviais ou irrigações; contudo, na medida em que os dias de secagem se acumulam, ela passa a ficar mais elevada no solo em plantio direto.

5. A técnica de microlisímetros é adequada para a medição de valores absolutos e relativos de evaporação da água do solo, em plantio direto e preparo convencional.

\section{Agradecimentos}

Ao Conselho Nacional de Desenvolvimento Científico e Tecnológico, pelo apoio financeiro; à Coordenadoria de Aperfeiçoamento de Pessoal de Nível Superior, pelas bolsas de Mestrado.

\section{Referências}

AASE, J.K.; TANAKA, D.L. Soil water evaporation comparisons among tillage practices in the northern great plains. Soil Science Society of American Journal, v.51, p.436-440, 1987.

AYDIN, M.; YANG, S.L.; KURT, N.; YANO, T. Test of a simple model for estimating evaporation from bare soils in different environments. Ecological Modeling, v.182, p.91-105, 2005.

BARCELOS, A.A.; CASSOL, E.A.; DENARDIN, J.E. Infiltração de água em um Latossolo Vermelho-Escuro sob condições de chuva intensa em diferentes sistemas de manejo. Revista Brasileira de Ciência do Solo, v.23, p.35-43, 1999. 
BERGAMASCHI, H.; GUADAGNIN, M.R.; CARDOSO, L.S.; SILVA, M.I.G. da. Clima da estação experimental da UFRGS (e região de abrangência). Porto Alegre: UFRGS, 2003. 78p.

BOAST, C.W.; ROBERTSON, T.M. A 'micro-lysimeter' method for determining evaporation from bare soil: description and laboratory evaluation. Soil Science Society of American Journal, v.46, p.689-696, 1982.

BRAGAGNOLO, N.; MIELNICZUK, J. Cobertura do solo por resíduos de oito seqüências de cultura e seu relacionamento com a temperatura e umidade do solo, germinação e crescimento inicial do milho. Revista Brasileira de Ciência do Solo, v.14, p.91-98, 1990.

CHEN, S.Y.; ZHANG, X.Y.; PEI, D.; SUN, H.Y.; CHEN, S.L. Effects of straw mulching on soil temperature, evaporation and yield of winter wheat: field experiments on the North China Plain. Annals of Applied Biology, v.150, p.261-268, 2007.

DALMAGO, G.A. Dinâmica da água no solo em cultivos de milho sob plantio direto e preparo convencional. Porto Alegre: UFRGS, 2004. 245p.

DALMAGO, G.A.; BERGAMASCHI, H.; BERGONCI, J.I.; KRÜGER, C.A.M.B.; COMIRAN, F.; HECKLER, B.M.M. Retenção e disponibilidade de água às plantas, em solo sob plantio direto e preparo convencional. Revista Brasileira de Engenharia Agrícola e Ambiental, v.13, p.855-864, 2009.

DE VITA, P.; DI PAOLO, E.; FECONDO, G.; DI FONZO, N.; PISANTE, M. No-tillage and conventional tillage effects on durum wheat yield, grain quality and soil moisture content in southern Italy. Soil \& Tillage Research, v.92, p.69-78, 2007.

FABRIZZI, K.P.; GARCÍA, F.O.; COSTA, J.L.; PICONE, L.I. Soil water dynamics, physical properties and corn and wheat responses to minimum and no-tillage systems in the southern Pampas of Argentina. Soil \& Tillage Research, v.81, p.57-69, 2005.

HATFIELD, J.L.; SAUER, T.J.; PRUEGER, J.H. Managing soils to achieve greater water use efficiency: a review. Agronomy Journal, v.93, p.271-280, 2001.

HUBERT, F.; HALLAIRE, V.; SARDINI, P.; CANER, L.; HEDDADJ, D. Pore morphology changes under tillage and no-tillage practices. Geoderma, v.142, p.226-236, 2007.

JI, S.N.; UNGER, P.W. Soil water accumulation under different precipitation, potential evaporation, and straw mulch conditions. Soil Science Society of American Journal, v.65, p.442-448, 2001 .

KUNZ, J.H.; BERGONCI, J.I.; BERGAMASCHI, H.; DALMAGO, G.A.; HECKLER, B.M.M.; COMIRAN, F. Uso da radiação solar pelo milho sob diferentes preparos do solo, espaçamento e disponibilidade hídrica. Pesquisa Agropecuária Brasileira, v.42, p.1511-1520, 2007.
LEMON, E.R. The potentialities for decreasing soil moisture evaporation loss. Soil Science Society of America Journal, v.20, p.120-125, 1956.

MARTORANO, L.G.; BERGAMASCHI, H.; DALMAGO, G.A.; FARIA, R.T. de; MIELNICZUK, J.; COMIRAN, F. Indicadores da condição hídrica do solo com soja em plantio direto e preparo convencional. Revista Brasileira de Engenharia Agrícola e Ambiental, v.13, p.397-405, 2009.

MOITRA, R.; GHOSH, D.; SARKAR, S. Water use pattern and productivity of rainfed yellow Sarson (Brassica rapa L. var. glauca) in relation to tillage and mulching. Soil \& Tillage Research, v.38, p.153-160, 1996.

MORET, D.; ARRÚE, J.L. Dynamics of soil hydraulic properties during fallow as affected by tillage. Soil \& Tillage Research, v.96, p.103-113, 2007.

MORET, D.; ARRÚE, J.L.; LÓPEZ, M.V.; GRACIA, R. Influence of following practices on soil water and precipitation storage efficiency in semiarid Aragon (NE Spain). Agricultural Water Management, v.82, p.161-176, 2006.

RODRIGUES, T.R.I.; BATISTA, H.S.; CARVALHO, J.M. de; GONÇALVES, A.O.; MATSURA, E.E. Uniformidade de distribuição de água em pivô central, com a utilização da técnica TDR na superfície e no interior do solo. Revista Brasileira de Engenharia Agrícola e Ambiental, v.5, p.187-191, 2001.

ROJAS, C.A.L. Alterações físico-hídricas de um podzólico em função do manejo de solo. 1998. 77p. Dissertação (Mestrado) Universidade Federal do Rio Grande do Sul, Porto Alegre.

SANTOS, O.A.; BERGAMASCHI, H.; ROSA, L.M.G.; BERGONCI, J.I. Calibrated heat-pulse method for the assessment of maize water uptake. Scientia Agricola, v.57, p.27-31, 2000.

SAUER, T.J.; HATFILD, J.L.; PRUEGER, J.H. Corn residue age and placement effects on evaporation and soil thermal regime. Soil Science Society of America Journal, v.60, p.1558-1564, 1996.

TAHIRI, A.Z.; ANYOJI, H.; YASUDA, H. Fixed and variable light extinction coefficients for estimating plant transpiration and soil evaporation under irrigated maize. Agricultural Water Management, v.84, p.186-192, 2006.

WARD, P.R.; WHISSON, K.; MICIN, S.F.; ZEELENBERG, D.; MILROY, S.P. The impact of wheat stubble on evaporation from a sandy soil. Crop \& Pasture Science, v.60, p.730-737, 2009.

YANG, M.D.; YANFUL, E.K. Water balance during evaporation and drainage in cover soils under different water Table conditions. Advances in Environmental Research, v.6, p.505-521, 2002.

YUAN, C.P.; LEI, T.W.; MAO, L.L.; LIU, H.; WU, Y. Soil surface evaporation processes under mulches of different sized gravel. Catena, v.78, p.117-121, 2009.

Recebido em 13 de maio de 2010 e aprovado em 19 de julho de 2010 